\title{
How to assess? Perceptions and preferences of undergraduate medical students concerning traditional assessment methods
}

\author{
Anita Holzinger ${ }^{1,2}$, Stefan Lettner ${ }^{2}$, Verena Steiner-Hofbauer ${ }^{1}$ and Meskuere Capan Melser ${ }^{1 *}$ (D)
}

\begin{abstract}
Background: Medical students' perception of traditional assessments have an important impact on their approaches to learning. Even though these assessment formats such as Multiple-Choice Question (MCQ), Short Answer Question (SAQ) or oral examinations, are frequently used in medical curricula, only little is known about student's perceptions of these assessments. The objective of this study was to assess perceptions and preferences of undergraduate medical students concerning traditional assessment formats.

Methods: The study was conducted at the Medical University of Vienna. Attitudes of 2nd year undergraduate medical students towards traditional assessment formats, and their relation to students' learning, and students' attitude towards objectivity, was inquired using a self-developed questionnaire.

Results: 459 students participated in this study. MCQs examinations were the most preferred assessment format and were chosen as the most objective format. Most students agreed that oral examinations are more appropriate for achieving long-term knowledge. Female students showed higher preference for oral examinations than male students. Students would prefer an assessment mix of 41.8\% MCQs, 24.0\% oral examinations, and 9.5\% SAQs, if they were free to choose the assessment tools.

Conclusion: Students prefer MCQ format over SAQs/oral examinations. Students' subjective perception of the importance of gaining long-term knowledge through an assessment has no influence on their assessment preference.
\end{abstract}

Keywords: Traditional assessments, Perceptions of undergraduate medical students, Preferences

\section{Background}

Assessments in higher education have several functions, including grading, evaluation of student achievement and supporting student's learning. How to assess in medical education is still the subject of many controversial discussions. Traditional assessment methods like traditional or structured oral examinations, Multiple

\footnotetext{
* Correspondence: meskuere.capanmelser@meduniwien.ac.at ${ }^{1}$ Research Unit for Curriculum Development, Teaching Center/Medical University of Vienna, Spitalgasse 23, Bauteil 87, A-1090 Vienna, Austria Full list of author information is available at the end of the article
}

Choice Question (MCQ) formats, and Short Answer Question (SAQ) formats have been widely criticised for different reasons. Even though MCQ format is an efficient assessment method for universities with large student cohorts - it is objective, transparent, economic, and enables to measure students' knowledge up to competence level - this format can danger the cumulative learning and long-term retention of medical knowledge $[1,2]$. Besides, writing a higher order thinking MC question can be challenging for item writers $[3,4]$. SAQ format in turn, can test a wide range of topics with high

C C The Author(s). 2020 Open Access This article is licensed under a Creative Commons Attribution 4.0 International License, which permits use, sharing, adaptation, distribution and reproduction in any medium or format, as long as you give appropriate credit to the original author(s) and the source, provide a link to the Creative Commons licence, and indicate if changes were made. The images or other third party material in this article are included in the article's Creative Commons licence, unless indicated otherwise in a credit line to the material. If material is not included in the article's Creative Commons licence and your intended use is not permitted by statutory regulation or exceeds the permitted use, you will need to obtain permission directly from the copyright holder. To view a copy of this licence, visit http://creativecommons.org/licenses/by/4.0/. The Creative Commons Public Domain Dedication waiver (http://creativecommons.org/publicdomain/zero/1.0/) applies to the data made available in this article, unless otherwise stated in a credit line to the data. 
reliability [5] but, the evaluation of results is time consuming and is therefore not feasible as an instrument for testing a large number of students [6]. Finally, oral examinations enable the instructors to measure for example clinical competence of students or to judge students associative and strategic thinking. The use of oral examinations has been criticized because of low reliability, low validity, and examiners bias [7, 8]. Additionally, Cees van der Vleuten stated that the utility of an assessment method depends on its reliability, validity, costs, educational impact and its acceptability $[9,10]$.

During the last decade, the investigation of students' assessment preference has gained increased attention due to understanding factors that drive the learning process and its outcomes. Research findings point out that students' perceptions of assessment have considerable influence on students' approaches to learning and studying [11]. Vice versa, students' assessment perception influences their evaluation of the lecturers and lectures [11, 12]. Furthermore, students' preferences of assessment reflect their perception of learning environment, their learning conceptions, and their approaches to learning $[11,13]$. When students asked for their perception of learning approaches by using different assessment techniques, three main approaches are identified [11]. Surface approaches intend to address an association between routine memorisation and procedural problem solving [1416]. In contrast, deep approaches to learning lead from an intention to understanding and are associated with active conceptual analysis $[15,16]$. The third one, the strategic or achieving approach, described as intention to achieve the highest possible grades by using well-organised and conscientious study methods $[14,15]$. As assessment is one of the defining features of the students' approaches to learning [17-19], Marton and Saljo investigated the relationship between assessment and students' approaches to learning, and found that students' preferred assessment requirements are strongly related with their approaches to learning [18]. Similarly, Ramsden found that students often explained surface approaches or negative attitudes in terms of their experiences of inappropriate forms of assessment [19, 20]. Entwistle and Tait also found that the types of assessment do have influence on the way how students learn [21]. For example, multiple choice question formats push students towards surface approaches, while open, essay type questions encourage them to pursue a deep level of understanding [21], and a long-term knowledge achieving. Students with surface learning approaches mostly prefer multiple choice tests viewing it as being easier to prepare, easier to take, less complex, more interesting, less tricky, and fairer [22]. Also, students' intention for achieving higher relative scores leads them to develop positive attitudes towards MCQ format [14, 15]. And similarly students with poor learning skills, who have low confidence in their academic ability, prefer MCQ format over other types of traditional assessments [23]. On the other hand, studies showed that students with good learning skills and high competence in their academic ability tend to prefer the essay type of assessment to the MCQ format [23]. Overall, assessment formats seem to have a considerable impact on students' approaches to learning; and students' perception of assessment and their approaches to learning seem to be strongly related [11].

As far as we know, there are only few studies that studied the perception of medical students towards traditional assessment tools. Findings of these studies present that the majority of medical students prefer MCQ format as summative assessment over open-ended or essay evaluations [24-26]. Oral examination are not very popular among medical students because of their lack of objectivity and examiner bias [24].

Even though deep learning should be an achievable learning approach at higher medical education, assessments like MCQ formats, which force students to surface approach, are widely spread examination tools. This holds also for the Medical University of Vienna where examinations consist of 45\% MCQ formats, 15\% SAQ formats and 40\% other assessments such as oral examinations, OSCE, key-feature questions, mini-clinical evaluation exercise (mini-Cex), direct observation of procedural skills (DOPs) and self-assessment. Currently efforts are being made to alter the examinations, particularly changes in the mix of the various assessment formats are being discussed. The intended reforms will be guided by recent results of research in the didactics of medical education. To facilitate the implementation of changes, also students' views on this issue will be taken into consideration. Until now only a few studies on students' perceptions of examination modalities have been published, showing a preference for the MCQ format [24-26]. We therefore decided to carry out a survey aimed at exploring 3rd semester medical and dental students' opinions on summative integrated assessment formats such as MCQ, SAQ, and traditional oral examinations, with which students are familiar from the beginning of their medical education. First, we were interested in students' preferences regarding these assessment formats. Second, we aimed at finding out students' views on assessment characteristics like difficulty, length, and content of assessment. We also wanted to understand how the assessment formats affect students' intention to achieve long-term medical knowledge. Third, we wanted to investigate students' perception of the objectivity of the various assessment formats. Additionally, we explored students' views about how variable the usage of assessment methods should be, if they were free to choose.

\section{Methods}

\section{Questionnaire}

In order to gain insight into the attitudes of medical and dental students towards traditionally used assessment formats, the Research Unit in cooperation with the 
Assessment \& Skills Department of the Teaching Center kindly asked the students to participate in this study. A self-created questionnaire was handed out to third semester medical students $(n=459)$ during mandatory courses. 194 female students and 251 male students (44 dental students and 391 medical students) volunteered to fill out the anonymous questionnaire. All students signed a declaration of consent. The study was approved by the data protection and clearing committee of the MedUni Wien.

The questionnaire was based on recently used summative assessment methods, their long-lasting effect on medical students learning, and their objectivity, difficulty, content and duration. Along with sociodemographic information such as sex (11 students did not answer this question) and education (dental or medical medicine, 24 students did not answer this question) the questionnaire included 5 different parts that addressed opinion, expectation, aspiration of undergraduate medical and dental students on various assessment methods used in medical education as well as attitudes of medical students towards concept of teaching/learning activity.

The questionnaire measured levels of agreement on a four level ordinal scale ranging from "strongly disagree" to "strongly agree". Questions related to extent criteria such as difficulty, duration and content of assessment measured levels of opinion on a three level ordinal scale. Further specific question regarding the mix of assessment methods in percentage was included to seek more detail about the assessment preference of students if they were free to choose. In total, $84.9 \%$ of all questions were completed.

\section{Statistical methods}

Data was entered using SPSS version 24. Statistical analysis were done by using R 3.6.0 [27]. Mean values and bootstrapped $95 \%$ confidence intervals were calculated for all results. Graphics were created using ggplot 2 [28]. Percentage responses to mixed assessment questions which did not sum up to $100 \%$ were scaled accordingly. The correlation between students' perception and assessment methods was analysed by using spearman's rho.

The cumulative link mixed model has been used to analyse the students' assessment preference [29]. Students ID has been chosen as a random factor, assessment methods, long-term learning, and objectivity of assessment and students' satisfaction have been used as fixed explanatory factors.

\section{Results}

Most of the students preferred MCQs over oral examinations and short answer questions (mean 3.18, SD \pm 0.89 for MCQs; mean 2.34, SD \pm 0.94 for oral examination; and mean 2.15, SD \pm 0.89 for SAQs) (Fig. 1). Most students found oral examinations more appropriate for

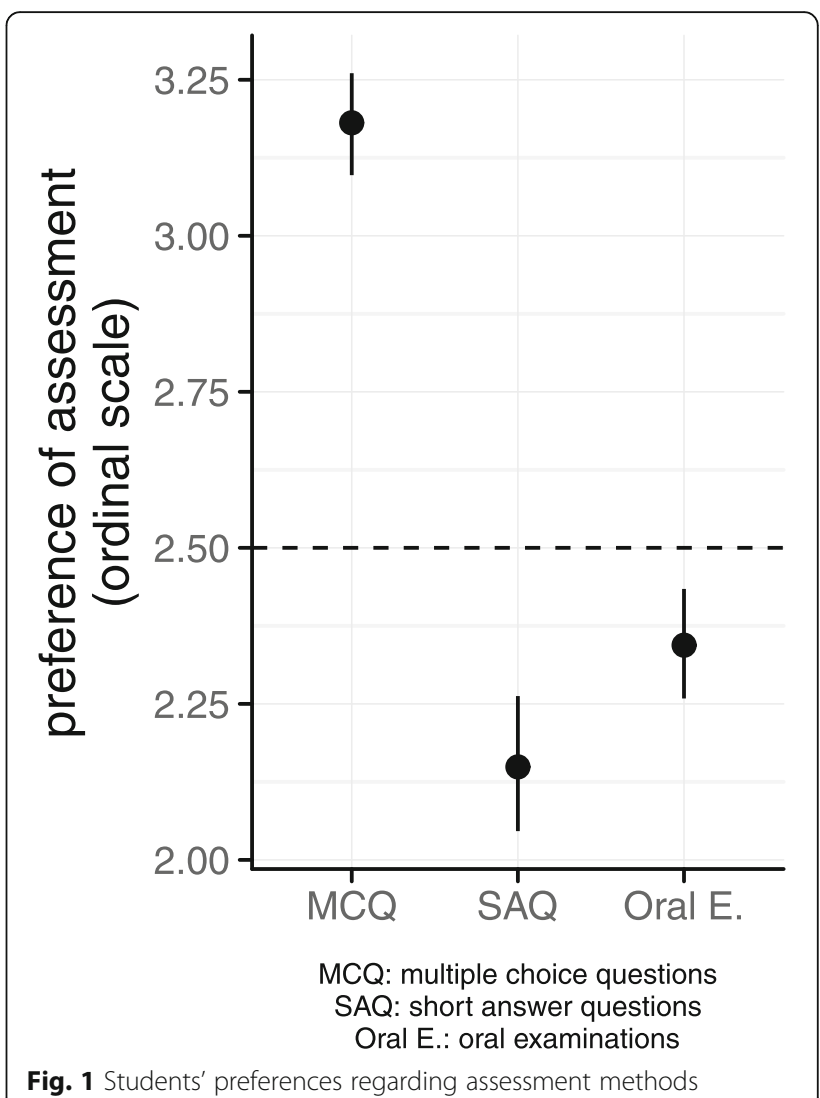

achieving long-term knowledge than MCQs and SAQs (mean 3.42, $\mathrm{SD} \pm 0.65$; mean 2.27, $\mathrm{SD} \pm 0.87$; and mean 2.52, $\mathrm{SD} \pm 0.83$ ) (Fig. 2).

Additionally, oral examinations were considered less objective than SAQs and MCQs (mean 1.83, SD \pm 0.79 ; mean 2.97, $\mathrm{SD} \pm 0.73$; and mean $3.72, \mathrm{SD} \pm 0.53$ ). The majority of students judged MCQs as an objective tool (Fig. 3). In addition, significant gender differences emerged with respect to the oral examination format, with female students having more favourable attitudes than male students. The correlation coefficient of students' perception towards oral examination is $r=0.60$ for female and $r=0.34$ for male students.

Students' response was obtained regarding extent criteria such as difficulty of assessment, duration of assessment and content of assessment. The difficulty of assessments was rated by students appropriately. There was no significant difference between MCQs, SAQs and oral examinations (mean 2.05, $\mathrm{SD} \pm 0.36$; mean 2.22, $\mathrm{SD} \pm 0.45$; and mean 2.17, $\mathrm{SD} \pm 0.41$ ) (Fig. 4). Student's rating of assessment duration was reasonable and there was no difference between various methods (mean 1.98, $\mathrm{SD} \pm 0.32$ for SAQs and mean $2.03, \mathrm{SD} \pm 0.26$ for oral examination) (Fig. 4). The students were also asked about the quantity of examination material, and most students found that the content of assessments are a lot 


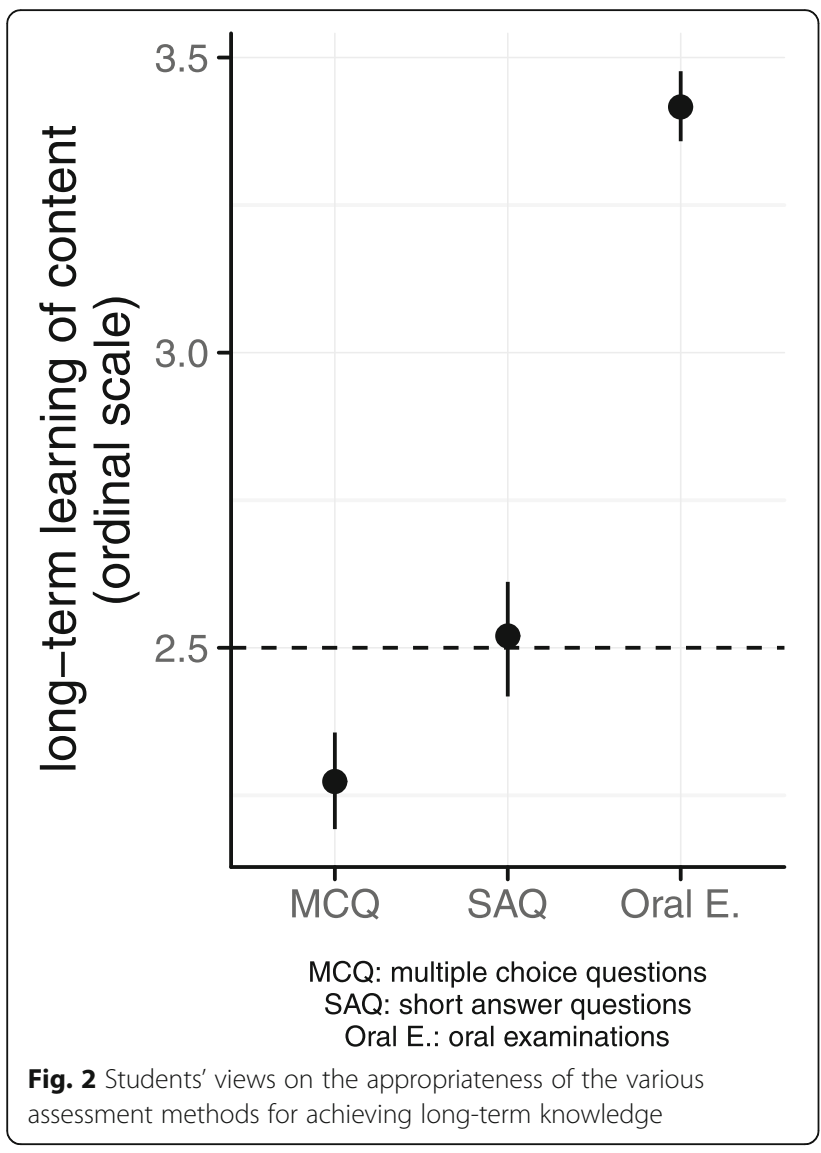

to learn (mean 2.42, $\mathrm{SD} \pm 0.50$ for SAQs; mean 2.27, $\mathrm{SD} \pm 0.46$ for oral examinations).

Were students free to choose, they would prefer a mix of $41.8 \%$ MCQs, $24.0 \%$ oral examinations, 9.5\% SAQs, and $24.7 \%$ other assessment methods such as OSCE and openended questions. Most students choose MCQs as the main assessment format followed by oral examinations.

Modelling assessment preference of students showed that in general, MCQs were highly preferred over SAQs (log odds -2.53$)$ and oral examinations (logs odds 2.80 ). This preference was mainly modified by student appraisal of long-term learning (log odds increase by 3.58 from negative to positive appraisal), followed by general satisfaction (increase by 1.57 from negative to positive) and objectivity of assessment methods (increase by 1.18 from negative to positive). In comparison with other factors, the difficulty of assessment was perceived least important (decrease by 0.83 from too easy to too difficult) (Table 1, Fig. 5). All of the above-mentioned factors were significant $(p<0.001)$.

\section{Discussion}

Aim of this study is to assess students' perception of traditional assessment methods and to examine the impact of students' learning activity on their preferences.

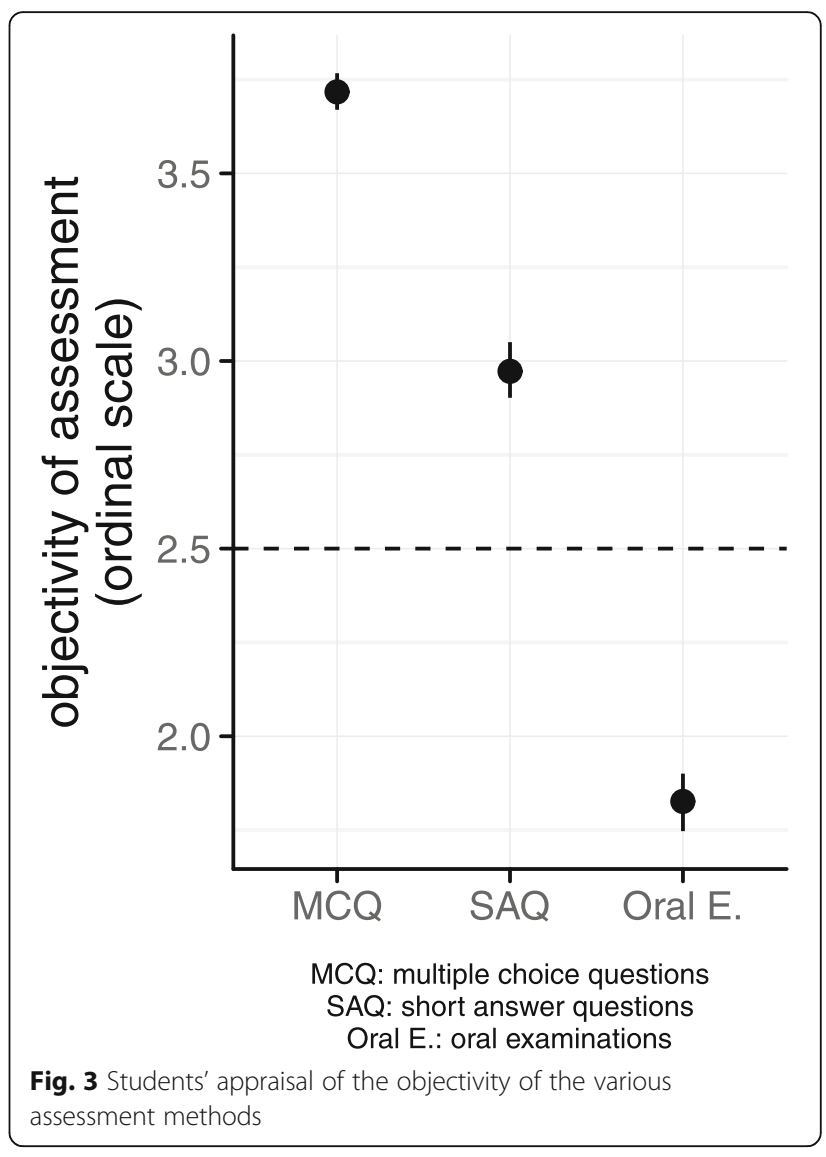

This study also aimed at understanding the relation between students' perception of assessment and objectivity in assessment.

The results show that students perceive MCQ format more favourable than SAQ format and oral examinations. Students' higher perceived objectivity and general satisfaction give preference to this assessment format.

MCQs have been widely used for summative assessment in undergraduate medical education because of their convenient standardization, efficient testing for large classes and a broad sampling of knowledge [30]. Wellconstructed MCQs allow the evaluation of taxonomically higher-order cognitive skills such as application of knowledge, interpretation, and synthesis rather than the test of recall of isolated facts [31]. Our study showed that most of the students prefer MCQ format to SAQs and oral examinations on the grounds that this examination seems easier to prepare for and easier to pass, which is in agreement with other studies [24, 25,32].

SAQs have been commonly used in examinations to assess the basic knowledge and understanding of a topic. SAQs tend to test higher-level thinking and assesses mainly knowledge, comprehension, and some application if they can incorporate clinical scenarios. In this study, students evaluated SAQs less favourably. Most 


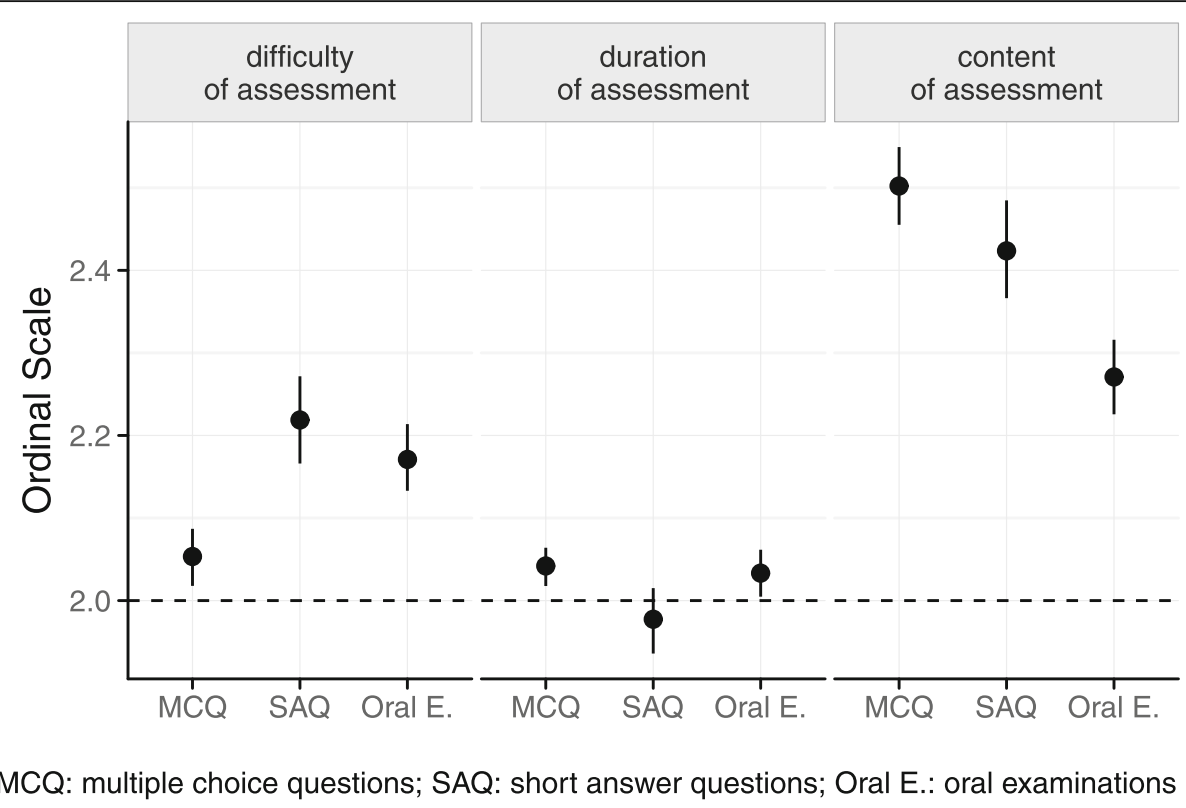

Fig. 4 Students' judgment of the difficulty, duration and content of the various assessments

students found that SAQs were more difficult than MCQs and oral examinations. On the other hand, studies showed that the attitudes towards each of these assessment formats correlated with students' learningrelated processes of the cognitive and affective aspects. Students with good learning skills, who have high confidence in their academic ability, tend to prefer SAQ type of assessment over the multiple choice type of assessment [23]. Nevertheless, these results do not apply to our students. In their view, SAQs do not encourage long-term retention of medical knowledge, and are less objective in comparison to MCQ format. Our students also found that oral examinations invoke long-term retention of medical knowledge more than MCQs and SAQs and are more preferred than SAQ format.
Furnham et.al. demonstrated that multiple choice questions are preferred by bright, and less open candidates, and oral exams are better suited for stable, low conscientious students with a deep learning style [33]. It has been also suggested that students with a deep study approach tend to prefer essay-type questions, while students with a surface study approach tend to prefer multiple choice formats [13]. In contrast to this study, in our model, we tried to understand the factors that influence the assessment preference of students in undergraduate medical education, and showed that long-term retention has not the greatest influence on exam preference., Students using deep approaches to learning for examinations still tend to prefer MCQs over oral examinations, despite the fact that they found oral

Table 1 Estimates for log odds and corresponding confidence intervals in the mixed logistic ordinal model

\begin{tabular}{|c|c|c|c|c|}
\hline Assessment methods & Short Answer Questions (SAQs) & -2.53 & -2.93 & -2.14 \\
\hline & Oral Examinations & -2.8 & -3.33 & -2.27 \\
\hline \multirow[t]{3}{*}{ Long-term Learning } & less & 1.44 & 0.97 & 1.91 \\
\hline & rather than & 2.47 & 1.96 & 2.99 \\
\hline & more & 3.58 & 2.98 & 4.2 \\
\hline \multirow[t]{2}{*}{ Difficulty of Assessment } & too difficult & -0.99 & -1.34 & -0.64 \\
\hline & too easy & -0.16 & -0.94 & 0.63 \\
\hline \multirow[t]{3}{*}{ Satisfaction of Students } & less & 0.52 & -0.01 & 1.06 \\
\hline & rather than & 1.1 & 0.55 & 1.65 \\
\hline & more & 1.57 & 0.92 & 2.23 \\
\hline \multirow[t]{3}{*}{ Objectivity of Assessment } & less & 0.42 & 0.02 & 0.81 \\
\hline & rather than & 0.89 & 0.4 & 1.38 \\
\hline & more & 1.18 & 0.63 & 1.72 \\
\hline
\end{tabular}




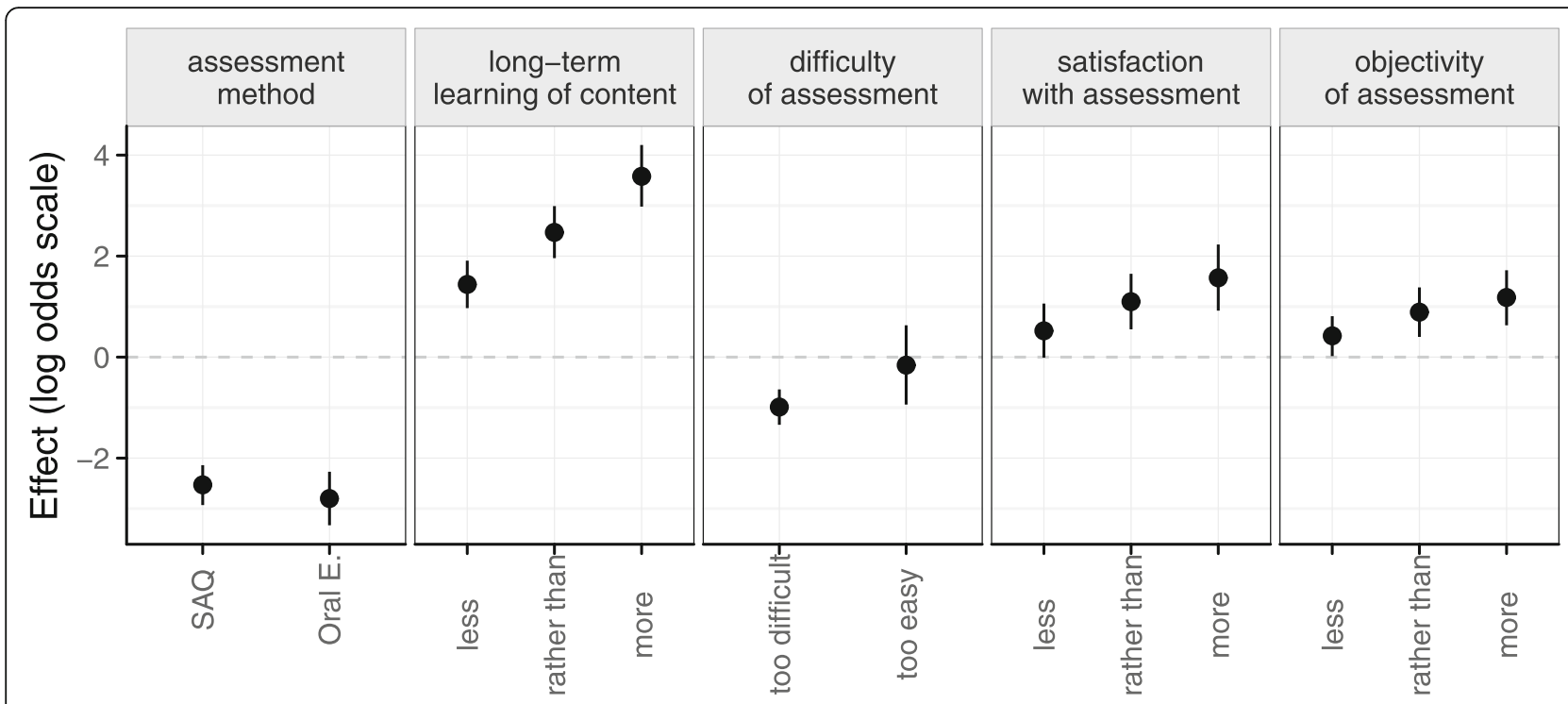

SAQ: short answer questions; Oral E.: oral examinations

Fig. 5 Graphic representation of Table 1

examinations encouraging long-term retention of medical knowledge. Our conclusion is that MCQ format is easier to learn and the structure of MCQ formats allows an economical approach to learning.

Some studies report gender effects on students' preferences of assessments. In this study, we also observed gender differences, with female students having more favourable attitudes towards oral examinations than males. Birenbaum and Feldman demonstrated that MCQ formats are considered less favourable by females than males in comparison to essay examinations [23]. Other studies also showed that gender causes high differences in preferences of written exams [34]. The reasons could be 1) the relationship between preference and personal dimension of risk taking [35]; for example: females were more reluctant than males to guess on MCQs and were more likely to leave items blank; or 2) the relation between personality traits and preference of assessment methods. Another possible explanation could be that oral examinations may bepreferred by women, because they converse with more questions and develop connections with others (in this case "examiners") through talking in contrast to men, who prefer direct statements and have a "get it done" approach [36].

As concerns the preferred mix of assessment formats, we found that the share of MCQ format examinations in our current curriculum meets students' expectations. Besides, students prefer oral examinations or other alternative assessment formats over SAQ examinations. Overall, the satisfaction of students with the various assessment methods in the curriculum determines how successful they will be in using their medical knowledge in the future.

Assessment drives learning in all forms of education including medical education [37]. Therefore, it is necessary to study students' attitudes towards different assessment formats before implementing a new curriculum. Students will be more motivated and hence even would perform better if they are assessed through methods of their choice.

\section{Conclusion}

In conclusion, our results provide an additional information and evidence on students' perceptions about traditional assessment formats, and students' satisfaction about gaining long-term knowledge through these assessments, which can be an important guide to improve their assessment practices, and to achieve a higher quality of learning and education.

\section{Limitations}

Only the opinion of students who were in second year of undergraduate medical education could be obtained. We also did not try to evaluate student learning style (surface approaches vs. deep approaches) and student performance in respect to distribution rates, which would have been related to our study. Due to the small number of dental students a comparison with medical students was not feasible. 


\section{Abbreviations}

MCQ: Multiple choice question; SAQ: Short answer question; OSCE: Objective structured clinical examination; DOPs: Direct observation of procedural skills; Mini-CEX: Mini-clinical evaluation exercise

\section{Acknowledgements}

We are especially grateful to the students who were participated in this study.

\section{Authors' contributions}

$\mathrm{AH}, \mathrm{VSH}$ and MCM was responsible for study concept. Study design was by $\mathrm{AH}$ and MCM. AH and MCM was the main contributor to acquisition of data. $\mathrm{AH}, \mathrm{SL}$ and $\mathrm{MCM}$ were involved in analysing and interpretation of data. $\mathrm{AH}$, $S L$ and MCM have been involved in drafting the manuscript and revising it critically for important intellectual content. AH, VSH, SL and MCM, have given final approval of the version to be published; have agreed to be accountable for all aspects of the work in ensuring that questions related to the accuracy or integrity of any part of the work are appropriately investigated and resolved.

\section{Funding}

No funding was obtained for this manuscript.

\section{Availability of data and materials}

The questionnaire used during this study is available from the corresponding author on reasonable request.

\section{Ethics approval and consent to participate}

The study was approved by the data protection/clearing committee of the Medical University of Vienna.

\section{Consent for publication}

Not applicable.

\section{Competing interests}

The authors declare that they have no competing interests.

\section{Author details}

${ }^{1}$ Research Unit for Curriculum Development, Teaching Center/Medical University of Vienna, Spitalgasse 23, Bauteil 87, A-1090 Vienna, Austria.

${ }^{2}$ University Clinic of Dentistry/Medical University of Vienna, Vienna, Austria.

Received: 13 September 2019 Accepted: 10 September 2020

Published online: 17 September 2020

\section{References}

1. Bauer D, Holzer M, Kopp V, Fischer MR. Pick-N multiple choice-exams: a comparison of scoring algorithms. Adv Health Sci Educ Theory Pract. 2011; 16(2):211-21.

2. Schuwirth LW. How to write short cases for assessing problem-solving skills. Med Teach. 1999;21(2):144-50.

3. Bridge PD, Musial J, Frank R, Roe T, Sawilowsky S. Measurement practices: methods for developing content-valid student examinations. Med Teach. 2003;25(4):414-21.

4. Scully D. Constructing multiple-choice items to measure higher-order thinking. Pract Assessment. 2017;22.

5. Wakeford RE, Roberts S. A pilot experiment on the inter-examiner reliability of short essay questions. Med Educ. 1979;13(5):342-4.

6. Sam A, Hameed S, Harris J, Meeran K. Validity of very short answer versus single best answer questions for undergraduate assessment 2016.

7. Colton T, Peterson OL. An assay of medical students' abilities by oral examination. J Med Educ. 1967:42(11):1005-14.

8. Foster $\pi$, Abrahamson S, Lass S, Girard R, Garris R. Analysis of an oral examination used in specialty board certification. J Med Educ. 1969:44(10):951-4.

9. van der Vleuten CP, Schuwirth LW. Assessing professional competence: from methods to programmes. Med Educ. 2005:39(3):309-17.

10. Van Der Vleuten CPM. The assessment of professional competence: developments, research and practical implications. Adv Health Sci Educ. 1996;1(1):41-67.
11. Struyven K, Dochy F, Janssens S. Students' perceptions about evaluation and assessment in higher education: a review. Assess Eval High Educ. 2005; 30(4):325-41.

12. Sander P, Stevenson K, King M, Coates D. University Students' expectations of teaching. Stud High Educ. 2000;25(3):309-23.

13. Birenbaum M. Assessment and instruction preferences and their relationship with test anxiety and learning strategies. High Educ. 2007;53(6):749-68.

14. Entwistle N, McCune V, Walker P. Conceptions, styles, and approaches within higher education: Analytical abstractions and everyday experience. In: Sternberg RJ, Zhang L-F, editors. The educational psychology series. Perspectives on thinking, learning, and cognitive styles Mahwah. NJ, US: Lawrence Erlbaum Associates; 2001. p. 103-36.

15. Entwistle N, Ramsden P. Understanding Student Learning 1983.

16. Trigwell K, Prosser M. Improving the quality of student learning: the influence of learning context and student approaches to learning on learning outcomes. High Educ. 1991;22(3):251-66.

17. Entwistle NJ. Approaches to learning and perceptions of the learning environment: introduction to the special issue. High Educ. 1991;22(3):201-4.

18. Marton F, Saljo R. Approaches to learning. In: Marton F, Hounsell D, Entwistle N, editors. The experience of learning. Edinburgh: Scottish Academic Press; 1997

19. Ramsden P. The context of learning in academic departments. In: Marton F, Hounsell D, Entwistle N, editors. The experience of learning. Implications for teaching and studying in higher education. Edinburgh: Scottish Academic Press; 1997. p. 198-271.

20. Ramsden P. 'A study of the relationship between student learning and its academic context' Unpublished PhD thesis, University of Lancaster. 1981.

21. Entwistle $\mathrm{N}$, Tait H. Approaches to learning, evaluations of teaching, and preferences for contrasting academic environments. High Educ. 1990;19(2):169-94.

22. Zeidner M. Essay versus multiple-choice type classroom exams: the Student's perspective. J Educ Res. 1987:80(6):352-8.

23. Birenbaum M, Feldman RA. Relationships between learning patterns and attitudes towards two assessment formats. Educ Res. 1998:40(1):90-8.

24. Amin TT, Kaliyadan F, Al-Muhaidib NS. Medical students' assessment preferences at King Faisal University, Saudi Arabia. Adv Med Educ Pract. 2011;2:95-103.

25. Ibrahim NK, Al-Sharabi BM, Al-Asiri RA, Alotaibi NA, Al-Husaini WI, Al-Khajah $\mathrm{HA}$, et al. Perceptions of clinical years' medical students and interns towards assessment methods used in King Abdulaziz University, Jeddah. Pak J Med Sci. 2015;31(4):757-62.

26. Rafique S, Rafique H. Student's feedback on teaching and assess-ment at Nishta Medical College, Multan. J Pak Med Assoc. 2013;63:1205-9..

27. RCoreTeam. R: A Language and Environment for Statistical Computing. R Foundation for Statistical Computing, Vienna, Austria. 2019;3.6.0( https:// www.r-project.org/)

28. Wickham H. ggplot2. Elegant Graphics for Data Analysis. New York: Springer; 2009. http://had.co.nz/ggplot2/.

29. Christensen RHB. Regression Models for Ordinal Data. R package version 2015 2015;6-28(https://github.com/runehaubo/ordinal).

30. Chandra S, Katyal R, Singh K, Singh A, Joshi HS. Creating valid multiplechoice questions (MCQs) bank with faculty development of pharmacology 2018. 359-66 p.

31. Case SM, Swanson DB. Constructing written test questions for the basic and clinical sciences. Philadelphia, PA: National Board of Medical Examiners; 2002.

32. O'Brien D, Richards J, Walton KE, Phillips MGA, Humphreys H. Survey of teaching/learning of healthcare-associated infections in UK and Irish medical schools. J Hosp Infect. 2009;73(2):171-5.

33. Furnham A, Batey M, Martin N. How would you like to be evaluated? The correlates of students' preferences for assessment methods 2011. 259-63 p.

34. Lakhal S, Sévigny S, Frenette E. Personality and preference for evaluation methods: A study among business administration students 2013. 103-15 p.

35. Ben-Shakhar G, Sinai Y. Gender differences in multiple-choice tests: the role of differential guessing tendencies. J Educ Meas. 1991;28(1):23-35.

36. Bailey S. Couple Relationships: Communication and Conflict Resolution. MSU Extension. 2009:17(2):via George Mason University Libraries.

37. Wormald BW, Schoeman S, Somasunderam A, Penn M. Assessment drives learning: an unavoidable truth? Anat Sci Educ. 2009;2(5):199-204.

\section{Publisher's Note}

Springer Nature remains neutral with regard to jurisdictional claims in published maps and institutional affiliations. 